\title{
Thermal Performance of Microinverters on Dual-axis Trackers
}

\author{
Mohammad A. Hossain ${ }^{a}$, Timothy J. Peshek ${ }^{a}$, Yifan Xu ${ }^{b}$, Liang Ji ${ }^{d}$, Jiayang Sun ${ }^{b}$, Alexis R. \\ Abramson $^{c}$ and Roger H. French ${ }^{a}$ \\ ${ }^{a}$ Solar Durability and Lifetime Extension Center, Case Western Reserve University, Cleveland, \\ $\mathrm{OH}, \mathrm{USA}$; \\ ${ }^{b}$ Center for Statistical Research, Computing and Collaboration, Department of Epidemiology \\ and Biostatistics, Case Western Reserve University, Cleveland, OH, USA; \\ ${ }^{c}$ Department of Mechanical and Aerospace Engineering, Case Western Reserve University, \\ Cleveland, OH, USA; \\ ${ }^{d}$ Underwriters Laboratories, Northbrook, IL, USA.
}

\begin{abstract}
Time-series insolation, environmental, thermal and power data were analyzed in a statistical analytical approach to identify the thermal performance of microinverters on dual-axis trackers under real-world operating conditions. This study analyzed 24 microinverters connected to 8 different brands of photovoltaic (PV) modules from July through October 2013 at the Solar Durability and Lifetime Extension (SDLE) SunFarm at Case Western Reserve University. Exploratory data analysis shows that the microinverter's temperature is strongly correlated with ambient temperature and PV module temperature, and moderately correlated with irradiance and AC power. Noontime data analysis reveals the variations of thermal behavior across different brands of PV module. Hierarchical clustering using the Euclidean distance measure principle was applied to noontime microinverter temperature data to group the similarly behaved microinverters. A multiple regression predictive model has been developed based on ambient temperature, PV module temperature, irradiance and AC power data to predict the microinverters temperature connected with different brands PV modules on dual-axis trackers.
\end{abstract}

Keywords: Microinverters, Thermal performance, Temperature prediction, Statistical analytics, Modeling

\section{INTRODUCTION}

Photovoltaic (PV) installations using microinverters are becoming quite common, especially in the residential market. A microinverter is designed to connect with one PV module, and it converts the DC power output of the PV module to utility AC.

Advantages of a microinverter installed PV system include maximum power point tracking (MPPT) for individual PV modules with no single-point of failure of the PV system. In addition, the absence of the high voltage DC line provides a safer operating environment compared to its counterpart: string inverters. The potential mismatch from shading of PV modules, which are very common in residential PV systems, do not reduce the performance of the total PV array, unlike a string or central inverter equipped PV system. ${ }^{1}$

Reliability has always been a critical concern for the growth of the PV industry, specifically the reliability of the string inverter system. ${ }^{2-4}$ Microinverter converter topology differs to that of typical string inverter in the necessary voltage boost ratio from input to output. Higher boost ratios may place higher levels of stress on the components of the converter. and therefore, they are both expected to experience similar kinds of reliability problem at real-world operation. The metal oxide semiconductor field-effect transistors (MOSFETs), capacitors, inductors, diodes, transformers, and circuit boards are considered as the critical to lifetime performance (CLP) components for string inverter and microinverter system. ${ }^{4,5}$

Further author information: (Send correspondence to Roger H. French.)

Roger H. French.: E-mail: roger.french@case.edu 
Capacitors are located at the DC input side of the microinverter. Capacitors store the input DC power and filter out the ripple current to ensure a continuous supply of current. In general, the electrolytic capacitors are used in single-stage microinverters, and the lifetime of the electrolytic capacitors are limited by the operating environment temperature. At higher operating temperatures, the aqueous component of electrolytes can evaporate, and increases the equivalent series resistance (ESR) of the capacitor. ${ }^{6,7}$ Therefore, more dissipative heat generates inside the capacitors, which in turns accelerates the evaporation rate of the electrolytes. As a result, the capacitance value of the capacitor decreases and eventually leads to capacitor dry out failure. Input ripple currents also generate additional heat inside the capacitors. Moreover, ripple current amplitude increases as the capacitance reduces, which will ultimately cause more internal heating, and drive the microinverters further towards capacitor failures.

MOSFETs or the switching transistors are the most failure-prone component in the inverter system. ${ }^{8,9}$ The thermal stress is the dominant stress behind the MOSFETs failure. Thermal stress can develop in the MOSFET die package due to rapid heat build up in the die as observed in the case of insulated-gate bipolar transistor (IGBT) during power cycling. ${ }^{10,11}$

Circuit boards and inductors are the hottest components in an inverter. ${ }^{5}$ Cyclic thermal stress can lead to solder fatigue, and also produce ferrite cracking in inductors

Thermal stress is the common dominant stress behind the failure or degradation for most of the CLP components. Therefore, predicting the thermal behavior or the internal temperature of the microinverter in real-world operation can provide insights into thermal stress development in the microinverter and help to assess the microinverter reliability. In real-world operation, thermal stress in microinverters can be developed from various heat and energy sources. The typical DC to AC power conversion efficiency of microinverter is approximately $96 \%$, and the remaining $4 \%$ is lost as heat in the system. Another significant source of thermal stress for the microinverter can be the PV module backsheet temperature, since the inverter is typically mounted directly below the module. The PV module absorbs solar energy and converts a fraction of it to DC electrical power. The residual solar energy increases the PV module temperature. The warm PV module radiates heat energy. The radiated heat energy from the PV module backsheet is incident on the microinverters and eventually develops into the thermal stress in the microinverter. Ambient temperature, wind speed and irradiance are some other important factors behind the development of thermal stress that will be studied herein to develop a predictive model for microinverter temperature.

Microinverters are placed in the outdoors underneath the PV modules, and they experience a broad range of climate conditions, including hot-dry, hot-humid, and freezing, for example. Different climate conditions can introduce different degradation mechanisms on the microinverters. Currently, the modern microinverter manufacturers use the accelerated lifetime test (ALT) based on IEC61215 ${ }^{12}$ to determine the reliability of the microinverters. The indoor accelerated test in the environmental chamber can introduce one or several stressors where real-world operation is a unique combination of multiple stressors. Therefore, it is impossible to simulate the precise combination of multiple stressors in environmental chamber to mimic the real-world. Thus the ALT cannot capture the entire set of degradation mechanisms of real-world operation. For example, the first-generation microinverters showed poor reliability in the real-world operating conditions even after passing the accelerated tests in the environmental test chambers ${ }^{13}$ The Solar Durability and Lifetime Extension (SDLE) Center have established a highly instrumented unique testbed, SDLE SunFarm, at Case Western Reserve University to study PV systems, materials, and components under real-world operating conditions. ${ }^{14}$ In an effort to characterize the real-world thermal performance of the microinverters, the SDLE SunFarm has conducted a study on the microinverters connected to different brands of PV modules in real-world operating conditions. In this study, a data science approach is presented to develop a linear predictive model for microinverter temperature.

\section{TEST SITE: SDLE SUNFARM}

The test site is located in the SDLE SunFarm(latitude $41.50^{\circ}$, longitude $-81.64^{\circ}$ ) on west campus of Case Western Reserve University in Cleveland, Ohio. The total size of the SunFarm is about one acre and peak power output is $35 \mathrm{KW}$. The whole SunFarm is divided into 16 electrical sites (Figure 1). Sites 1 and 2 are fixed rack mounted and rest are dual-axis trackers. Site 6,12 and 14 (marked with red box in Figure 1) are the dual-axis trackers where the 24 microinverters comprising this study cohort are installed. 


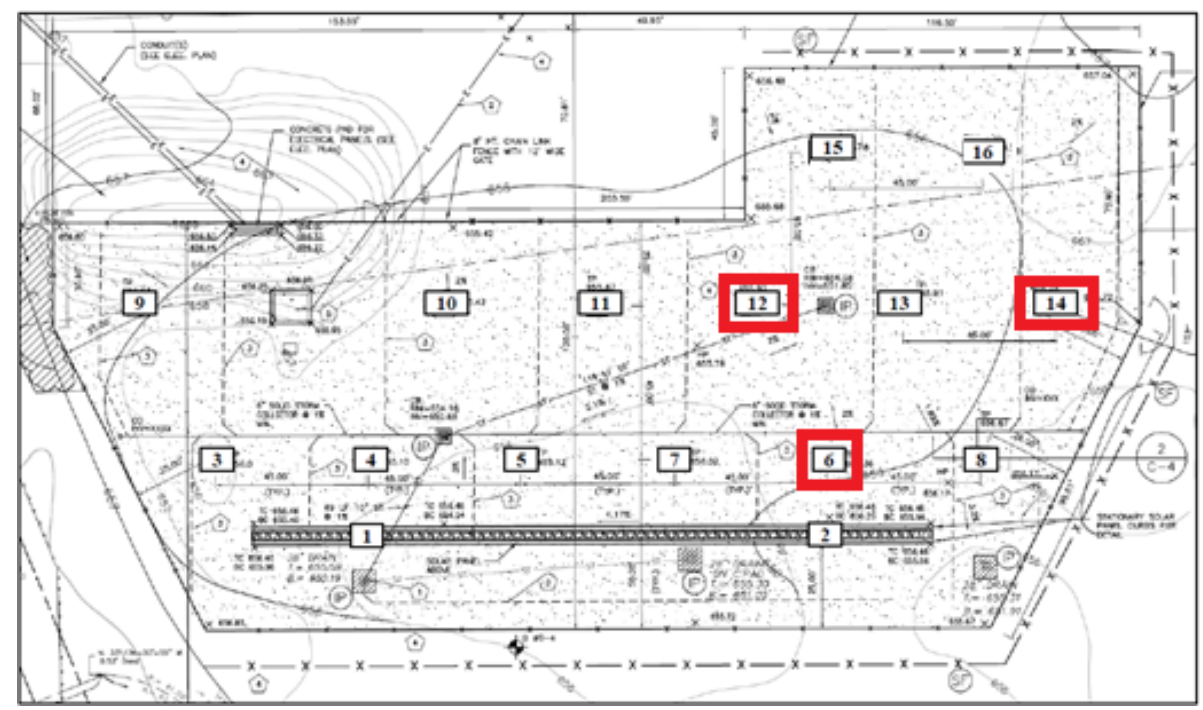

Figure 1. SDLE SunFarm layout and dual-axis tracker position. The studied microinverters are installed at the dual-axis tracker sites marked with red boxes

\subsection{Metrology Platform and Data Acquisition}

The SDLE SunFarm is equipped with a well instrumented metrology platform for weather, insolation, temperature and power monitoring. The Vaisala WXT520 weather transmitter was used to collect the environmental data: ambient temperature, wind speed, wind direction, relative humidity, and rain. Kipp\&Zonen CMP11 pyranometer was used to measure insolation data. T-type thermocouples from Omega Engineering Inc. were used to measure the PV module backsheet temperature and the microinverter temperature. The thermocouples were attached to the hottest point on the backsheet of the PV modules and microinverters, as determined by IR images collected during a time of peak power input to the inverters.

Through power line communication, the Enphase Envoy device collect the power data: DC voltage and current, AC power, and frequency. Campbell CR1000 data loggers and multiplexers collect the environmental, insolation, and temperature data every minute and store all the collected data in a central database every two hours. The Power data is reported by the Enphase Envoy to the Enphase enlighten website every 5 minutes. The power data is automatically acquired from the Enphase enlighten website using the Java Selenium web driver package and stored in the central database of the SDLE Center. Later, all data: power, insolation, temperature and climate, are ingested into the SDLE Center's informatics and analytics infrastructure, known as Energy CRADLE $^{\mathrm{TM}}{ }^{14}$

\subsection{Experimental Design Overview}

24 Enphase M215 microinverters were analyzed in this study from July through October 2013. The microinverters were connected to $24 \mathrm{PV}$ modules from 8 different brands. The baseline power of different brands of PV modules are listed in Table 1. Baseline DC power was measured by the SPIRE4600 solar simulator. ${ }^{15}$ The letters "K", "L", "O", "P", "Q", "R", "S" and "T" represent the different PV module brands in Table 1 and t\# corresponds to the site and tracker location, for example, P.t12 represents PV module brand P at tracker 12 .

\section{DATA ANALYSIS}

\subsection{Exploratory Data Analysis}

The environmental and thermal time-series raw data were validated by sensor cross-checks, ${ }^{16}$ then the time stamp of the raw data collected from different sensors or sources were checked with cross correlation functions (using ccf function from $\mathrm{R}$ statistics software ${ }^{17}$ ) to determine and account for any time lags. The time-series data were slewed according to their time lags to match their time formats. Multivariate graphical Exploratory 
Table 1. Baseline DC power of different brands of PV modules.

\begin{tabular}{|c|c|c|}
\hline Brand & Baseline power (W) & Standard deviation (W) \\
\hline K.t6 & 225.19 & 2.59 \\
\hline L.t6 & 231.02 & 4.12 \\
\hline O.t12 & 241.14 & 1.65 \\
\hline P.t12 & 231.75 & 0.95 \\
\hline Q.t12 & 212.86 & 4.98 \\
\hline R.t14 & 231.375 & 1.53 \\
\hline S.t14 & 230.95 & 1.03 \\
\hline T.t14 & 232.20 & 2.47 \\
\hline
\end{tabular}

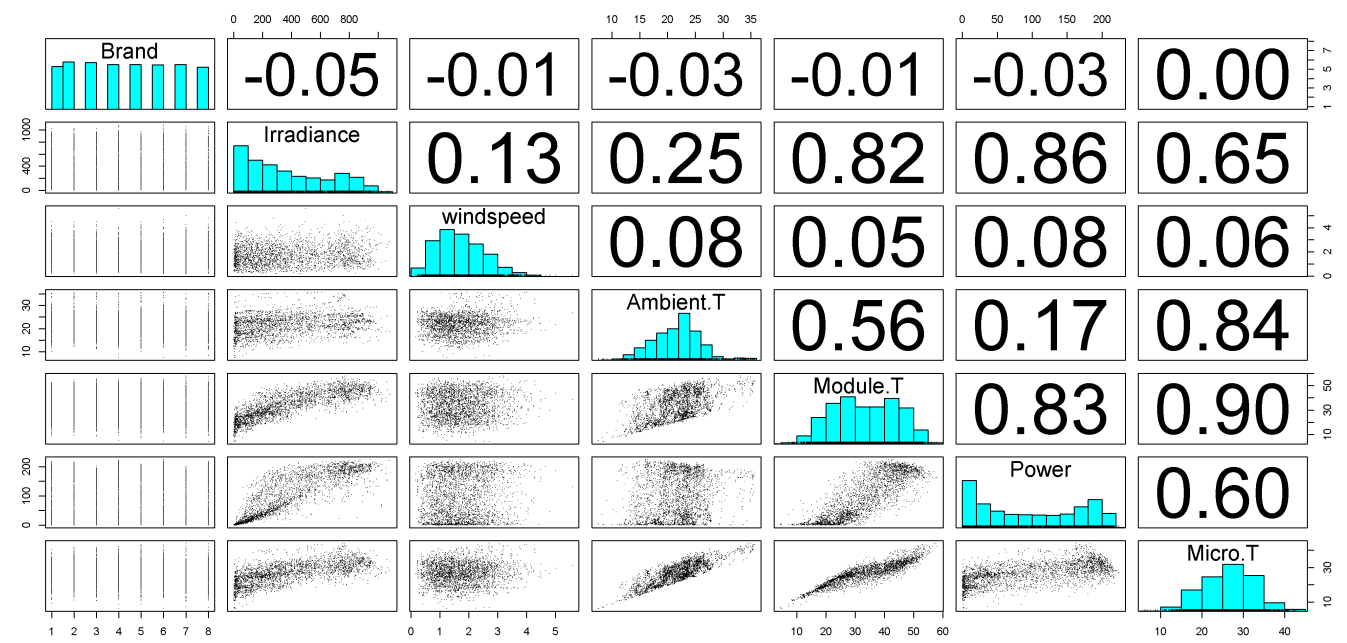

Figure 2. Pairwise scatter plots, histograms and correlation coefficients for the microinverters connected with different brands of PV modules. Pairwise scatter plots are in the lower triangle boxes, histograms are in the diagonal boxes, and the upper triangle boxes represent the correlation coefficients between variables. ${ }^{\dagger}$

Data Analysis (EDA) processes were employed on the raw time-series data, and correlation coefficients among the variables were determined. Figure 2 shows the histogram, pairwise scatter plots, and correlation coefficients of 7 variables: PV module brand, irradiance, wind speed, ambient temperature, PV module temperature, AC power and microinverter temperature, for the slewed dataset. ${ }^{17-19}$ The diagonal boxes represent the histogram of the variables. The upper and the lower triangle of boxes represent the Pearson correlation coefficients and pairwise scatter plots between the variables, respectively. The data indicate that microinverter temperature is most strongly correlated with ambient temperature and PV module temperature. Furthermore, the AC power and irradiance are also moderately correlated with the microinverter temperature. Correlation coefficients among the variables are shown in Table $2 .{ }^{18}$

Table 2. Correlation coefficients of different variables with microinverter temperature.

\begin{tabular}{|c|c|c|c|c|c|c|}
\hline Time & Brand & Irradiance & Ambient.T & Wind speed & Module.T & Power \\
\hline Full & 0 & 0.65 & 0.84 & 0.06 & 0.9 & 0.6 \\
\hline Morning hours & 0.01 & 0.25 & 0.98 & 0.07 & 0.89 & 0.12 \\
\hline Noon time & 0.05 & 0.61 & 0.82 & -0.01 & 0.91 & 0.59 \\
\hline
\end{tabular}

In order to isolate and observe the thermal attributes under low and high irradiance conditions, the date

\footnotetext{
${ }^{\dagger}$ Brand $=$ PV module brand, Ambient. $\mathrm{T}=$ Ambient temperature, Wind speed $=5$ point moving average wind speed, Module. $\mathrm{T}=\mathrm{PV}$ module temperature, Power $=$ AC Power, Micro. $\mathrm{T}=$ Microinverter Temperature
} 
Table 3. Average AC power, average PV module temperature difference with ambient temperature, and average microinverter temperature difference with ambient temperature at noon time. ${ }^{\S}$

\begin{tabular}{|l|l|l|l|l|l|l|}
\hline Brand & \multicolumn{2}{l}{ Power } & \multicolumn{2}{l|}{$\Delta$ Module.T } & \multicolumn{2}{|l|}{$\Delta$ Micro.T } \\
\hline & $\mathrm{W}$ & $\mathrm{SE}(\mathrm{W})$ & ${ }^{\circ} \mathrm{C}$ & $\mathrm{SE}\left({ }^{\circ} \mathrm{C}\right)$ & ${ }^{\circ} \mathrm{C}$ & $\mathrm{SE}\left({ }^{\circ} \mathrm{C}\right)$ \\
\hline P.t12 & 175.85 & 1.12 & 22.93 & 0.164 & 10.18 & 0.818 \\
\hline O.t12 & 185.95 & 1.16 & 22.25 & 0.154 & 8.94 & 0.064 \\
\hline Q.t12 & 168.74 & 1.05 & 23.32 & 0.159 & 8.95 & 0.066 \\
\hline R.t14 & 182.84 & 1.30 & 20.01 & 0.164 & 8.32 & 0.070 \\
\hline S.t14 & 183.01 & 1.32 & 21.05 & 0.165 & 7.54 & 0.072 \\
\hline K.t6 & 188.74 & 1.185 & 21.38 & 0.146 & 9.05 & 0.076 \\
\hline L.t6 & 170.83 & 1.026 & 22.66 & 0.154 & 8.77 & 0.068 \\
\hline T.t14 & 187.96 & 1.36 & 22.04 & 0.173 & 8.95 & 0.071 \\
\hline
\end{tabular}

format of full data set is transformed into local solar time (LST) and then two subsample data sets are created: morning hours and noon time. Morning hours is defined as LST between 5:00 to 6:30 and noon time is defined as 11:00 to 13:00 LST. The correlation coefficients of the subsample data sets are listed in Table 2. Additionally, the noon time average AC power output, average PV module temperature rise and average microinverter temperature rise are summarized in Table 3.

\subsection{Clustering Analysis}

Clustering is the a technique of assembling a sets of unlabeled data into several groups or clusters by conforming to their similarity. ${ }^{20}$ In this clustering study each data point (vector) contains all recorded noon time micorinverter temperatures corresponding to one of the eight brands. Thus every vector summarizes thermal behavior of the micorinverter throughout the window of the study. Figure 3 shows the dendrogram resulting from a hierarchical clustering, where Euclid distance is used as dissimilarity measure among vectors, and average linkage is used for merging clusters. The red boxes mark three distinct clusters in the dedrogram.

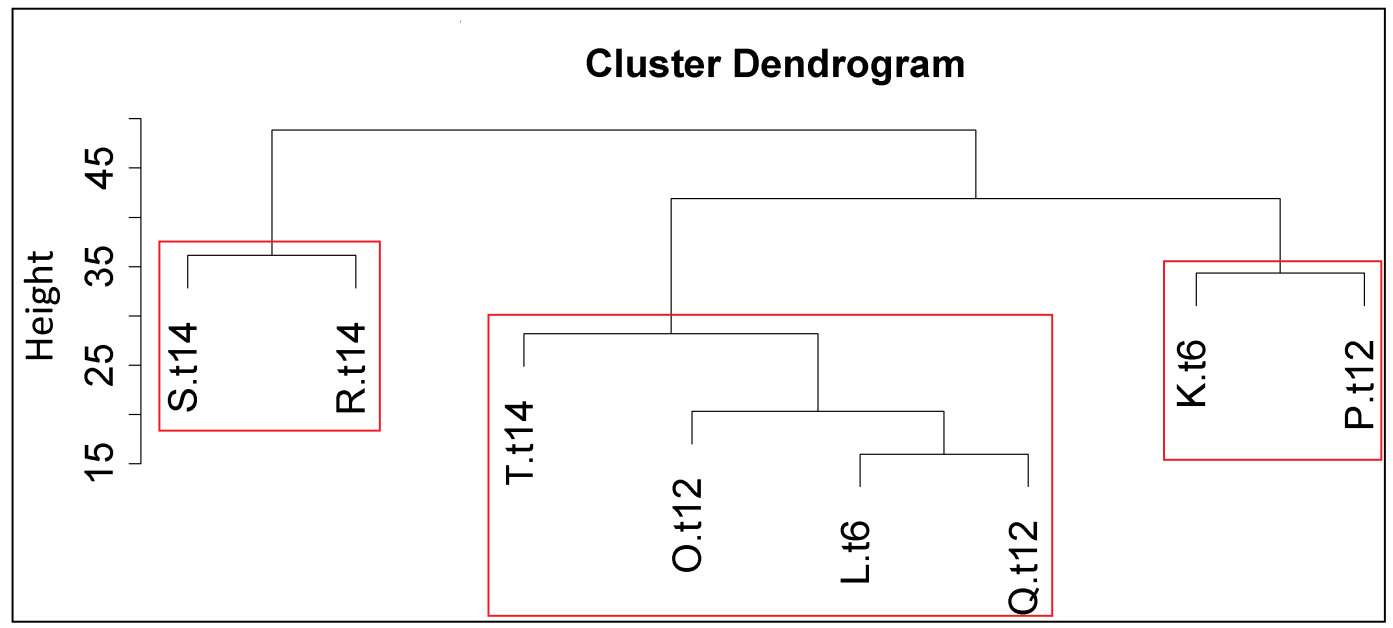

Figure 3. Hierarchical clustering diagram for microinverter temperature in the local solar noon time from July through October 2013.

\section{PREDICTIVE REGRESSION MODEL}

The relations between microinverter temperature and other factors is characterized through a multiple regression model with brands as a categorical variable. Various models were formulated using different subsets of all related variables, and the Akaike Information Criterion (AIC) $)^{21}$ value for each model was determined. The final model

\footnotetext{
${ }^{\S} \Delta$ Module. $\mathrm{T}=$ Module.T - Ambient.T, $\Delta$ Micro.T $=$ Micro.T - Ambient.T, $\mathrm{SE}=$ Standard error
} 
is determined by AIC value, aided with adjusted $R^{2}$ and domain knowledge. The residual plot of the final model shows a desired random pattern. In the final predictive model, the microinverter temperature (continuous variable) is predicted using two types of predictor variables: continuous and categorical. Ambient temperature, PV module temperature, AC power and irradiance are the continuous predictors and PV module brands are the categorical predictors. Since there is no reference brand, dummy variables with sum contrast were set on the PV module brands to capture the deviances of the thermal attributes of different brands from the average value.

$$
\begin{gathered}
\text { Micro.T }_{i}=\beta_{0}+\sum_{j=1}^{7} \beta_{0 j} x_{i j}+\alpha_{1} \text { Ambient. }_{i}+\alpha_{2} \text { Irradiance }_{i} \\
+\left(\beta_{1}+\sum_{j=1}^{7} \beta_{1 j} x_{i j}\right) \text { Module. } T_{i}+\left(\beta_{2}+\sum_{j=1}^{7} \beta_{2 j} x_{i j}\right) \text { Power }_{i}+\varepsilon_{i}
\end{gathered}
$$

Equation (1) represents the multiple linear regression predictive model equation for the microinverter temperature. $x_{i j}, j=1, \ldots, 7$ are dummy variables from the first 7 brands with sum contrast. That is, $x_{i j}=1$ if the $\mathrm{i}$-th observation is from brand $\mathrm{j}$, and $x_{i j}=0$ otherwise. $\varepsilon_{i}$ represents the errors associated with the predictive model. The adjusted r-squared value of the regression model is 0.9795 with residual standard error of $0.915^{\circ} \mathrm{C}$. $\beta_{0}, \alpha_{1}, \alpha_{2}, \beta_{1}$ and $\beta_{2}$, are the coefficients of mean model for intercepts, ambient temperature, irradiance, PV module temperature and $\mathrm{AC}$ power, whose values are listed in Table $4 . \beta_{0 j}, \beta_{1 j}$, and $\beta_{2 j}$ in Equation (1) (values listed in Table 5) represent the deviation in the coefficients of the intercepts, PV module temperature, and AC power from the mean model for seven brands of the PV modules. For the microinverters connected to the 8th PV module brand (S.t14), the coefficients of the predictive model can be calculated as follows: $\beta_{08}=-\left(\sum_{j=1}^{7} \beta_{0 j}\right)$, $\beta_{18}=-\left(\sum_{j=1}^{7} \beta_{1 j}\right), \beta_{28}=-\left(\sum_{j=1}^{7} \beta_{2 j}\right)$. The t-values (not shown) of the estimates of mean model coefficients suggest that, we can observe that, the ambient temperature and PV module temperature has a strong influence on microinverter temperature, and the impact of $\mathrm{AC}$ power on the microinverter temperature is less significant than the PV module temperature. The residual values of the model are distributed randomly, and do not show any particular pattern or trend which affirms the validation and the goodness of fit of the predictive model. Figure 4 shows comparison plots between actual and predicted microinverter temperature of the microinverters connected to the 8 different brands of PV module on a sunny day (09-04-2013). As can be seen from Figure 4, the predictive model predicts the microinverter temperature fairly well with some morning time over-prediction and afternoon time under-prediction.

Table 4. Correlation coefficients of the mean model for the linear regression predictive model for microinverter temperature.

\begin{tabular}{|c|c|c|c|c|c|}
\hline & Intercept & Ambient.T & Irradiance & Module.T & Power \\
& $\beta_{0}$ & $\alpha_{1}$ & $\alpha_{2}$ & $\beta_{1}$ & $\beta_{2}$ \\
\hline Mean & -0.447 & 0.678 & 0.002 & 0.364 & -0.014 \\
\hline
\end{tabular}

Table 5. Correlation coefficients of different variables for the PV module brand deviation from the linear regression predictive model of microinverter temperature.

\begin{tabular}{|c|c|c|c|}
\hline Brands & $\begin{array}{c}\text { Intercept } \\
\beta_{0 j}\end{array}$ & $\begin{array}{c}\text { Module.T } \\
\beta_{1 j} \times 10^{-2}\end{array}$ & $\begin{array}{c}\text { Power } \\
\beta_{2 j} \times 10^{-2}\end{array}$ \\
\hline R.t14 & 0.217 & 0.152 & 0.472 \\
\hline K.t6 & 0.348 & -1.166 & 0.317 \\
\hline P.t12 & 0.529 & -1.465 & 1.060 \\
\hline L.t6 & 0.054 & 1.525 & 0.674 \\
\hline O.t12 & 0.283 & -0.759 & 0.633 \\
\hline Q.t12 & 0.165 & -0.393 & 0.142 \\
\hline T.t14 & 0.104 & 0.964 & 0.357 \\
\hline
\end{tabular}




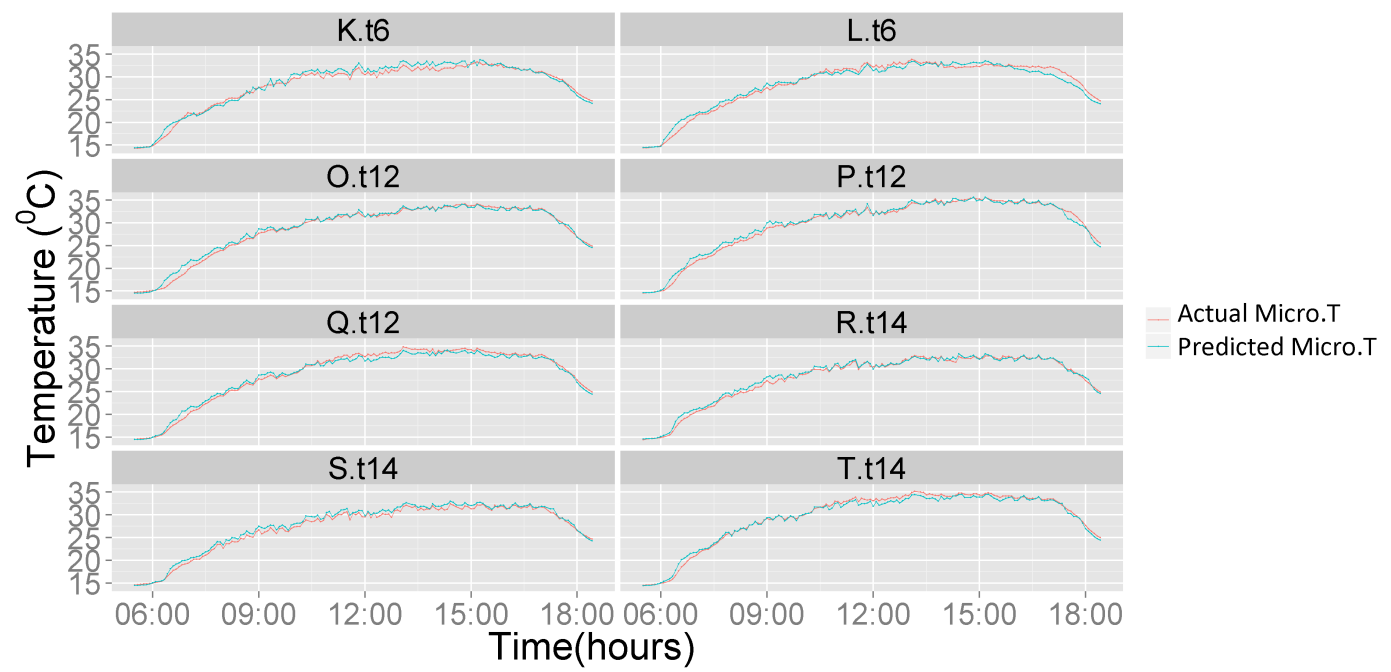

Figure 4. Comparison of actual and predicted microinverter temperature on a sunny day (09-04-2013)

\section{DISCUSSION}

The microinverters are shaded by the PV modules and therefore they do not have a direct interaction with solar irradiance. Therefore, irradiance is more strongly correlated with the PV module temperature than the microinverter temperature. Wind speed is an important variable since it determines the convective cooling rate of the PV module and microinverter. However, the pairwise scatter plots and the correlation coefficients values from Figure 2 and Table 2, show that the wind speed has poor correlation with the PV module and microinverter temperature or any other variables. The wind speed is measured by the weather transmitter. The weather transmitter is installed on top of a mounting pole at the SDLE SunFarm. Nonetheless, due to the height variations, tracker orientation and obstructions, the wind flow and wind profile may be more turbulent, or at least different from the weather transmitter at various dual-axis tracker platforms. Therefore, the wind speed shows poor correlation with every variable.

Table 3 summarizes the noon time average AC power output, and the temperature rise in the PV module and microinverter. The largest PV module temperature rise is noted in the Q.t12 PV modules; the lowest power producing PV modules. The temperature rise in PV modules with high power output (O.t12, S.t14, T.t14, R.t14, K.t6) are relatively small. The highest microinverter temperature is recorded in the P.t12 microinverters where a substantial temperature rise (approximately $22.93^{\circ} \mathrm{C}$ ) is noticed in the P.t12 PV module with moderate AC power output (around $175.85 \mathrm{~W}$ ). Figure 3 shows the clustering dendrogram of the noon time microinverter temperature. The dendrogram is divided into three major clusters (marked by red boxes in the Figure 3 ). The leftmost cluster consists of the S.t14 and the R.t14 microinverter temperature. The average AC power output and PV module temperature during noon are very similar for the S.t14 and the R.t14 system (Table 3), therefore the thermal performances of the S.t14 and the R.t14 microinverters are similar to each other. The central cluster contains the T.t14, the O.t12, the L.t6 and the Q.t12 microinverter temperature with the L.t6 and the Q.t12 microinverter temperature in the same sub-cluster. The L.t6 and the Q.t12 microinverter temperature are located in the same sub-cluster due to their similar AC power output and PV module temperature. The third cluster contains the K.t6 and the P.t12 microinverter temperature. Even though, the K.t6 and the P.t12 microinverter temperature are in the same cluster, significant differences are observed in their AC power output and PV module temperature (Table 3). Similar differences in AC power production are also noticed between the L.t6 \& the Q.t12 and the T.t14 \& the O.t12 systems in the central cluster. These clustering behaviors could be a topic for future work where PV module temperature and AC power will be explored to explain the clustering behaviors.

In the multiple regression predictive model, a continuous response variable (microinverter temperature) is predicted by both continuous and categorical predictor variables. The t-values of the coefficients of the predictive model of Equation (1) imply, it can be concluded that the impact of PV module temperature is more significant 
than the impact of AC power output of the system. In the predictive model, brand variation was not applied on ambient temperature and irradiance as brand variation for the ambient temperature and irradiance is not significant, and this variety was also covered by the PV module temperature and AC power variation across the brands. Figure 4 shows the prediction comparison between different PV modules brands on a sunny day where over-prediction of microinverter temperature is observed for all brands at the event of sharp temperature rise during $6 \mathrm{AM}$ to 7:30 AM LST. The predictive model also under predicts during noon and afternoon. Thermal mass and thermal diffusivity of the microinverter materials are some of the possible reasons for the over or under-prediction behavior of the predictive model. In the morning, when the irradiance value starts increasing, the microinverter temperature also starts rising. The predictive model of Equation (1) predicts a sharp increase in the microinverter temperature in the morning. However, the temperature rise in microinverter in real-world operation is relatively slower than the predictive model due to the thermal diffusivity of microinverter potting material.

\section{FUTURE WORKS}

For future analysis, it is also important to conduct studies on real-world fixed rack and rooftop PV systems in addition to the dual-axis trackers employed for this study since the convective cooling rate is different for different types of PV module mounting systems. For example, wind access to rooftop PV system is very limited compared to the PV system in the dual-axis trackers. Therefore, the microinverters in a fixed rack mounted rooftop PV systems have to operate at higher temperature than those studied herein, and critical components will endure greater thermal stress. The SDLE SunFarm is a part of a global SunFarm network. ${ }^{14}$ Under this SunFarm network, similar studies will be setup in different SunFarms of different climate zones which will provide us the opportunity to gather insights and help us to understand the real-world thermal behavior of microinverters under different weather conditions. The predictive linear regression model shows over and under-prediction. Future research will also focus on combining the thermal diffusivity of microinverter material into the predictive model. In addition, the change in thermal mass of the PV system throughout the day will be explored to alleviate the over and under-prediction issue.

\section{CONCLUSION}

A multiple linear regression predictive model for the microinverter temperature has been developed for the microinverters connected to the different brands of PV modules installed on dual-axis trackers. The predictive linear regression model is a function of ambient temperature, $\mathrm{PV}$ module temperature, AC power, irradiance, and their interactions; the statistically significant variables related to the microinverter temperature. From this study we can conclude that the PV module temperature is the dominant predictor of the microinverter temperature. Therfore, high power producing PV modules provide less thermal stress to the microinverter since the PV module temperature is determined by the difference between absorbed solar energy and maximum DC output power of the PV module. It is thus more advantageous to the long term performance of the microinverter to match the power handling capability of the microinverter to the PV module instead of allowing the microinverter to enter a power saturation state.

\section{ACKNOWLEDGMENTS}

This research work is funded by the Underwriter's Laboratories (UL), and the research was performed in the SDLE Center at Case Western Reserve University, established with Ohio Third Frontier funding under award Tech $11-060$, Tech 12-004. The authors would like to acknowledge the contributions of the members in the SDLE Center for their support of this study.

\section{REFERENCES}

[1] Koirala, B. P., Sahan, B., and Henze, N., "Study on MPP mismatch losses in photovoltaic applications," in [European Photovoltaic Solar Energy Conference and Exhibition (EU PVSEC)], 3727-3733 (2009). 
[2] Collins, E., Dvorack, M., Mahn, J., Mundt, M., and Quintana, M., "Reliability and availability analysis of a fielded photovoltaic system," in [Photovoltaic Specialists Conference (PVSC), 2009 34th IEEE], 002316002321, IEEE (2009).

[3] Kurtz, S., Granata, J., and Quintana, M., "Photovoltaic-reliability R\&D toward a solar-powered world," in [SPIE Solar Energy+ Technology], 74120Z-74120Z, International Society for Optics and Photonics (2009).

[4] Petrone, G., Spagnuolo, G., Teodorescu, R., Veerachary, M., and Vitelli, M., "Reliability issues in photovoltaic power processing systems," Industrial Electronics, IEEE Transactions on 55(7), 2569-2580 (2008).

[5] Sorensen, N. R., Thomas, E. V., Quintana, M. A., Barkaszi, S., Rosenthal, A., Zhang, Z., and Kurtz, S., "Thermal study of inverter components," Photovoltaics, IEEE Journal of 3(2), 807-813 (2013).

[6] Harada, K., Katsuki, A., and Fujiwara, M., "Use of ESR for deterioration diagnosis of electrolytic capacitor," Power Electronics, IEEE Transactions on 8(4), 355-361 (1993).

[7] Kulkarni, C. S., Biswas, G., Celaya, J. R., and Goebel, K., "Physics based degradation models for electrolytic capacitor prognostics under thermal overstress conditions,"

[8] Chan, F. and Calleja, H., "Reliability: A new approach in design of inverters for PV systems," in [International Power Electronics Congress, 10th IEEE], 1-6, IEEE (2006).

[9] Chan, F., Calleja, H., and Martinez, E., "Grid connected PV systems: A reliability-based comparison," in [Industrial Electronics, 2006 IEEE International Symposium on], 2, 1583-1588, IEEE (2006).

[10] Patil, N., Das, D., and Pecht, M., "A prognostic approach for non-punch through and field stop IGBTs," Microelectronics Reliability 52(3), 482-488 (2012).

[11] Patil, N., Menon, S., Das, D., and Pecht, M., "Anomaly detection of non punch through insulated gate bipolar transistors (IGBT) by robust covariance estimation techniques," in [Reliability, Safety and Hazard (ICRESH), 2010 2nd International Conference on], 68-72, IEEE (2010).

[12] Standard, I., "61215. crystalline Silicon Terrestrial Photovoltaic (PV) ModulesDesign qualification and Type Approval," International Electrotechnical Commission (1995).

[13] Rooij, P., Eikelboom, J., and Heskes, P., "Reliability testing of grid connected PV inverters," Netherlands Energy Research Foundation, ECN (2000).

[14] Hu, Y., Hosain, M. A., Jain, T., Gunapati, Y. R., Elkin, L., Zhang, G., and French, R. H., "Global sunfarm data acquisition network, energy CRADLE, and time series analysis," in [Energytech, 2013 IEEE], 1-5, IEEE (2013).

[15] Hu, Y., PV Module Performance Under Real-world Test Conditions-A Data Analytics Approach, Master's thesis, Case Western Reserve University (2014).

[16] Hossain, M. A., Thermal Characteristics of Microinverters on Dual-axis Trackers, Master's thesis, Case Western Reserve University (2014).

[17] R Core Team, R: A Language and Environment for Statistical Computing. R Foundation for Statistical Computing, Vienna, Austria (2013). ISBN 3-900051-07-0.

[18] Hossain, M. A., Peshek, T. J., Xu, Y., Ji, L., Abramson, A. R., and French, R. H., "Predictive Linear Regression Model for Microinverter Internal Temperature," in [Photovoltaic Specialists Conference (PVSC), 2014 40th IEEE], IEEE (2014).

[19] Revelle, W., psych: Procedures for Psychological, Psychometric, and Personality Research. Northwestern University, Evanston, Illinois (2014). R package version 1.4.5.

[20] de Vargas, R. R. and Bedregal, B. R., "Interval ckmeans: An algorithm for clustering symbolic data," in [Fuzzy Information Processing Society (NAFIPS), 2011 Annual Meeting of the North American], 1-6, IEEE (2011).

[21] Akaike, H., "Likelihood of a model and information criteria," Journal of econometrics 16(1), 3-14 (1981). 